Int. J. Electrochem. Sci., 11 (2016) 9340 - 9354

\title{
Analysis of Electrochemical Hydrogen Permeation through AISI Stainless and Welding Zones for Hydrogen Service
}

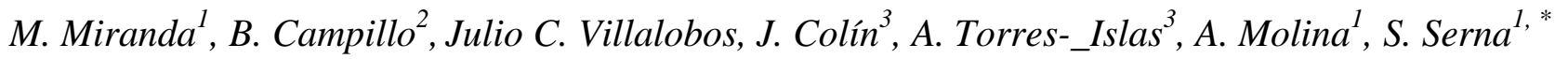 \\ ${ }^{1}$ Centro de Investigación en Ingeniería y Ciencias Aplicadas - (IICBA), Universidad Autónoma del \\ Estado de Morelos, Av. Universidad 1001, 62209 Cuernavaca, Morelos, Mexico, ${ }^{2}$ ICF- FQ UNAM, \\ Av. Universidad s/n Col Chamilpa Cuernavaca, Morelos, México, ${ }^{3}$ Facultad de Ciencias Químicas e \\ Ingeniería, P. A. Ingeniería Mecánica, Universidad Autónoma del Estado de Morelos, Av. Universidad \\ 1001, 62209 Cuernavaca, Morelos, México \\ *E-mail: aserna@uaem.mx
}

doi: $10.20964 / 2016.11 .60$

Received: 8 August 2016 / Accepted: 15 September 2016 / Published: 10 October 2016

\begin{abstract}
Stainless Steel proved to be very valuable material for humankind modern technology, today concepts like global warming and sustainable alternate technologies have become important concepts to actual human survival. One of the most sounded, reliable and ecofriendly technology was developed around a simple element, named hydrogen. Hydrogen economy, that is Fuel Cells System Economy, needs the use of hydrogen embrittlement resistance materials for housings, valves and springs, etc. From the vast possible materials two modern austenitic alloy AISI grades 304 and 316 types, were studied by high fugacity hydrogen conditions (electrochemical hydrogen charge) in smooth and welded specimens by the hydrogen permeability technique developed by Devanathan and Starchursky. Stainless steels are well known to be more resistance to hydrogen embrittlement effects, than ferritic steels. Recently austenitic 316 alloy has been proposed to fulfill hydrogen economy demands. However, more data are needed in order to identify hydrogen embrittlement mechanisms for this alloy and its welding condition. Austenitic alloy 304 was studied comparing smooth and TG welding conditions as well. The results reveal that alloy 316 has good performance under hydrogen embrittlement conditions its chemical composition modified with molybdenum infers different hydrogen embrittlement mechanisms related to austenitic alloy 304. The different carbides formed in both austenitic alloys give substantial differences in their microstructures that finally result in different interactions with hydrogen embrittlement mechanism. A relevant result is that apparently austenitic alloy 304 has more resistance to hydrogen embrittlement, this seems to be by the lack of formation of the chi phase that is more likely to be formed in austenitic alloy 316 . The TIG welding conditions for both stainless steels move the differences apart more between both stainless steel microstructures. Both stainless steels could be more susceptible to HE by their related mechanisms than in their respective HAZ and WZ.
\end{abstract}


Keywords: Hydrogen service, electrochemical hydrogen permeation, stainless steel, TIG welding, welding zones.

\section{$\underline{\text { FULL TEXT }}$}

(C) 2016 The Authors. Published by ESG (www.electrochemsci.org). This article is an open access article distributed under the terms and conditions of the Creative Commons Attribution license (http://creativecommons.org/licenses/by/4.0/). 